Provided for non-commercial research and education use. Not for reproduction, distribution or commercial use.

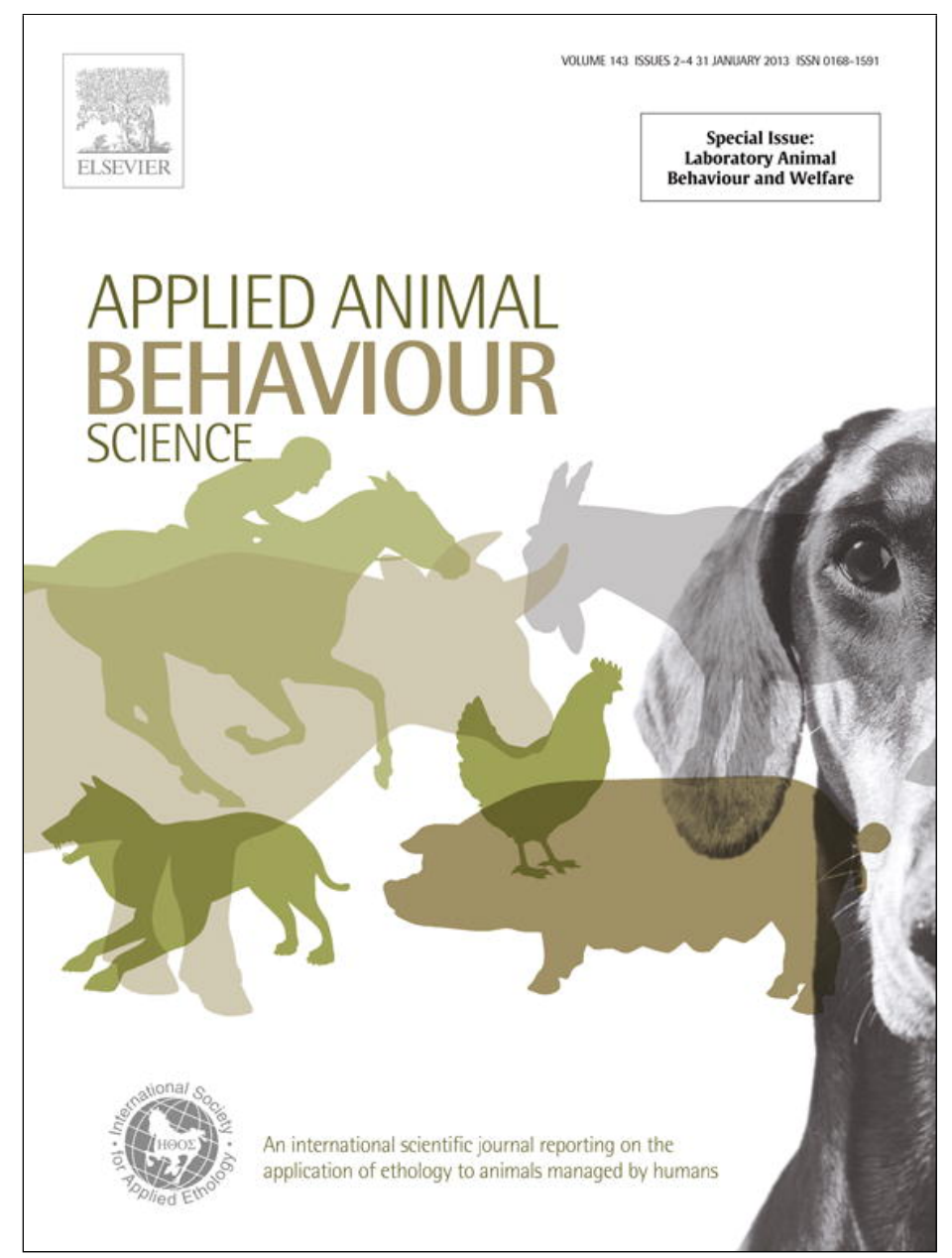

This article appeared in a journal published by Elsevier. The attached copy is furnished to the author for internal non-commercial research and education use, including for instruction at the authors institution and sharing with colleagues.

Other uses, including reproduction and distribution, or selling or licensing copies, or posting to personal, institutional or third party websites are prohibited.

In most cases authors are permitted to post their version of the article (e.g. in Word or Tex form) to their personal website or institutional repository. Authors requiring further information regarding Elsevier's archiving and manuscript policies are encouraged to visit:

http://www.elsevier.com/copyright 


\title{
Validating the use of a carbon dioxide laser for assessing nociceptive thresholds in adult domestic cats (Felis catus)
}

\author{
Mark J. Farnworth ${ }^{\mathrm{a}, *}$, Ngaio J. Beausoleil ${ }^{\mathrm{b}}$, Nigel J. Adams ${ }^{\mathrm{a}}$, Lorelle A. Barrett ${ }^{\mathrm{b}}$, \\ Mark Stevenson $^{\mathrm{b}}$, David G. Thomas ${ }^{\mathrm{c}}$, Mark R. Waterland ${ }^{\mathrm{d}}$, Natalie K. Waran ${ }^{\mathrm{e}}$, \\ Kevin J. Stafford ${ }^{\mathrm{b}}$ \\ a Animal Welfare and Biodiversity Research Group, Department of Natural Sciences, Unitec Institute of Technology, Private Bag 92025, \\ Auckland, 1025, New Zealand \\ b Institute of Veterinary, Animal and Biomedical Sciences, Massey University, Private Bag 11222, Palmerston North, 4442, New Zealand \\ c Institute of Food, Nutrition and Human Health, Massey University, Private Bag 11222, Palmerston North, 4442, New Zealand \\ d Institute of Fundamental Sciences, Massey University, Private Bag 11222, Palmerston North, 4442, New Zealand \\ e Jeanne Marchig International Centre for Animal Welfare Education, Royal (Dick) School of Veterinary Studies, The University of Edinburgh, \\ Easter Bush, Roslin, Midlothian, EH25 9RG, United Kingdom
}

\section{A R T I C L E I N F O}

\section{Article history:}

Available online 2 November 2012

\section{Keywords:}

Cat

$\mathrm{CO}_{2}$ laser

Nociception

Pain assessment

Repeatability

Threshold

\begin{abstract}
A B S T R A C T
Thermal sensitivity in cats has historically been assessed using complex devices which require direct application to the patient and can therefore, in themselves, affect the measurement. This study aimed to validate the use of a remote low power $(165 \mathrm{~mW})$ carbon dioxide laser device for the assessment of thermal nociceptive thresholds in cats. Repeatabilites were established based on individual responses to three thermal tests on the same day and across 4 consecutive days. A total of 12 thermal tests were conducted on each of eight male and eight female de-sexed adult cats. As a control a non-thermal helium aiming laser was used to ensure the animals were responding to the thermal component of the device. All thermal tests elicited a behavioural response with the large majority being a skin twitch known as the panniculus reflex (97\%). None of the non-thermal tests resulted in this reflex behaviour. There was no evidence that cats became sensitised or habituated to the low power thermal stimulus on any given day $(P=0.426)$ or across days $(P=0.115)$, or that there was any interaction between the two time factors $(P=0.084)$. There was also no difference in latency to respond between males and females $(P=0.094)$, although there was a significant interaction between the day of testing and the sex of the subject $(P=0.042)$. Significant intra-class correlations demonstrated that individual responses were repeatable over days 1-3 (all $P<0.05$ ) but not over day $4(P=0.096)$. A significant intra-class correlation was also evident across all days when data were combined $(P<0.0001)$. This technique shows some promise in assessing individual nociceptive thresholds and as a tool to establish associated individual differences. It could, with more exploration, also provide an alternative thermal mechanism for testing the efficacy of analgesics in cats. The significant repeatabilities were low ranging from 0.241 to 0.414 , this suggests that a number of extraneous factors may have influenced responses to $\mathrm{CO}_{2}$ laser stimulation at low power levels $(165 \mathrm{~mW})$. Further exploration of this technique on a larger sample than used here may allow elucidation of any other factors, including age or sex effects, that impact upon thermal sensitivity in the domestic cat.
\end{abstract}

(c) 2012 Elsevier B.V. All rights reserved.

\footnotetext{
* Corresponding author. Tel.: +64 $98154321 \times 7071$.

E-mail address: mfarnworth@unitec.ac.nz (M.J. Farnworth).
} 


\section{Introduction}

Cats are a commonly owned companion animal (Bernstein, 2005) and may be subjected to a number of surgical procedures to accommodate them in an anthropocentric environment. A range of surgical procedures are conducted to reduce reproductive rates (e.g. ovariohysterectomy; Grint et al., 2006; Rütgen et al., 2011; Waran et al., 2007) or damage to the owner's property (e.g. onychectomy; Cloutier et al., 2005). All involve tissue damage, and therefore result in pain. The provision of analgesia to cats prior to, during or following surgery, although improving, is not consistent (Robertson, 2005) and is underutilised in cats compared to dogs (Williams et al., 2005). It is therefore important to further investigate feline-specific pain and nociception, allowing improvements in understanding individual variation to be made, which may ultimately improve diagnoses and treatments.

Pain sensitivity is considered to be the point at which an animal is able to sense, and respond to, a noxious stimulus (Allen, 2004). Noxious stimuli have an actual (or perceived) ability to damage tissues (Woolf and Ma, 2007). Nociceptive tests that use behavioural responses as indicators have been identified as useful for the assessment of pain sensitivity in animals (Herskin et al., 2009) as the two are intrinsically linked. Sensitivity to noxious stimuli may vary between individual animals relative to their age (Gagliese and Melzack, 1999; Ting et al., 2010), sex (Chesterton et al., 2003; Fillingim and Gear, 2004; Greenspan et al., 2007) or prior experience, or may result from a complex interaction between multiple developmental factors (Guesgen et al., 2011). Increased pain sensitivity in cats may also result from central sensitisation during and following surgeries if effective peri-operative analgesia is not employed (Lascelles and Waterman, 1997). Therefore, reliable measurement of the sensitivity of cats to noxious stimuli is important and may ultimately improve the understanding of pain and analgesic effect.

Current methods for the assessment of nociceptive sensitivity and validation of analgesics in cats are relatively complex. They require direct manipulation of the subject and application of the stimulus to the skin using an attached device (e.g. pressure devices: Dixon et al., 2007; thermal devices: Dixon et al., 2002) as well as cutaneous measurement of temperature or applied force. These processes may affect the variables being measured and require significant time for habituation. In addition, directly applied thermal devices have been reported, in some cases, to be insufficiently sensitive to evaluate analgesia in cats (Taylor et al., 2007).

Measurement of thermal thresholds has been used to assess nociception and to evaluate analgesic effects in rats (Malmberg and Yaksh, 1992) and mice (Pinardi et al., 2003). In comparison, carbon dioxide $\left(\mathrm{CO}_{2}\right)$ lasers have been used to reliably assess thermal nociceptive thresholds in a range of species (e.g. sheep: Guesgen et al., 2011; pigs: Herskin et al., 2009; cows: Veissier et al., 2000). The benefits of $\mathrm{CO}_{2}$ laser stimulation include remote application, consistent stimulus application and immediate cessation of stimulation following the response. There is also complete absorbance of thermal energy by the skin, regardless of pigmentation (Gülsoy et al., 2001; Le Bars et al., 2001). In addition, laser stimulation followed by a clear behavioural response should require relatively little behavioural monitoring experience, particularly if the response is a stereotypic reflex, such as the panniculus reflex (a skin twitch), that has been associated with normal neural functioning (Van Soens et al., 2009).

To date, thermal devices used for threshold testing in cats have produced active behavioural responses (e.g. jumping or looking at the site of stimulation) (Slingsby et al., 2010) indicative of conscious pain perception. These thermal contact devices cannot be instantaneously removed from the subject to allow the site of application to cool rapidly. Previous thermal laser stimulation experiments in livestock have often used relatively high power outputs resulting in physical withdrawal of the target area (e.g. 2.25-4.5 W: Veissier et al., 2000). Where a range of power outputs have been used in pigs, increasing power has concomitantly reduced response latency as well as changed the type and frequency of the behaviour displayed (Herskin et al., 2009). It has also been suggested that low power output ( $2.5 \mathrm{~W}$ ) does not produce reliable measures of response in cattle (Veissier et al., 2000). It has not currently been established as to whether, in cats, low level stimulation resulting in a nociceptive response (panniculus), might be repeatable and could therefore be explored as a tool for measurement of sensitivity to pain.

This study investigates the repeatability of the response to a thermal laser device for use in testing the thermal nociceptive thresholds of cats. We hypothesise that the usefulness of such an approach depends on the repeatable nature of the response.

\section{Materials and methods}

\subsection{Subjects and housing conditions}

All procedures were approved by the Massey University Animal Ethics Committee (Massey University, Palmerston North, New Zealand, MUAEC protocol 11/49). The experiment used eight male and eight female, adult and de-sexed, domestic cats (Felis catus) with a mean age of 4.2 years (s.d. 1.5 years). The cats were permanently housed in a nutritional facility and were fed a standard wet cat food diet ad libitum during the trial. Cats were housed in stable colonies of 10 individuals in outdoor pens $(2.4 \mathrm{~m} \mathrm{H} \times 1.4 \mathrm{~m}$ $W \times 4.4 \mathrm{~m} L$ ); with approximately half the volume of each pen under cover.

During the experimental phase, six individual metabolism cages $(0.8 \mathrm{~m} H \times 0.8 \mathrm{~m} W \times 1.1 \mathrm{~m} \mathrm{~L})$ were used in a room adjacent to, but separate from, the colony housing area (see Hendricks et al., 1999). These cages were regularly used for nutritional trials during which the cats were isolated and allowed to feed. The cats were, therefore, familiar with the cages and single housing, avoiding the need to acclimatise the subjects. Although the cages housed a single cat, cats were, at all times, in visual contact with other individuals. The depth of each cage was reduced to $0.55 \mathrm{~m}$ using a cardboard wall to ensure the cat did not have access to a shelf at the rear of the cage and to prevent reflection of the laser from the plastic rear 
wall. The metal cage door was similarly replaced with a plastic coated square mesh with openings measuring $25 \mathrm{~mm} \times 25 \mathrm{~mm}$ to prevent reflection of the laser and subsequent injury to the subjects or operators. For the cats' comfort, and to encourage sternal recumbency by providing a slightly raised vantage point, each cage was furnished with a small wooden box and blanket. Food and water were not provided during the $1-1.5 \mathrm{~h}$ test phase.

\subsection{Experimental protocol}

\subsubsection{General procedure}

Approximately $24 \mathrm{~h}$ prior to the commencement of the study each cat was removed from the colony housing and a patch of fur was clipped to skin level from each side of the animal before they were returned to their colony cages. The area exposed measured approximately $4 \mathrm{~cm}^{2}$ on each side of the cat, starting at the third rib $1 \mathrm{~cm}$ sternally from the corresponding vertebra. Optimum positioning of the exposed area of skin (i.e. able to be accessed by the laser operator when the cat was in full sternal recumbency) was ascertained using two cats that did not participate in the subsequent study.

Each individual cat was tested every day for 4 consecutive days. Since all cats could not be housed in the test cages simultaneously, they were allocated to three groups of mixed sex, two of six individuals and one of four. The sequence in which these groups were tested was randomised across the 4 days to reduce any potential circadian effects. Testing began at 10:00 $\mathrm{h}$ and ended at 16:00 $\mathrm{h}$ with each group being in the test room for between 1 and $1.5 \mathrm{~h}$. Cats were returned to the colony cages between days but not between tests. On introduction to the test cage, each cat was allowed 15 min to settle; the experimenters and equipment remained in the room during this time to habituate the cats to their presence. The test sequence began when the majority of cats were quiet and in sternal recumbency.

\subsubsection{Laser device}

Thermal nociceptive thresholds were measured using a purpose-built remote laser device (M.P.B. Technologies Inc., Dorval, Canada). The $\mathrm{CO}_{2}$ laser produced a $5 \mathrm{~mm}$ diameter beam which was aimed using a non-thermal visible helium laser housed within the casing of the laser device. The wavelength of the thermal laser was $10.60 \mu \mathrm{m}$ (far infra-red) and the power output used was $165 \mathrm{~mW}$. Given that the non-visible component of the laser was potentially hazardous, personal protective equipment was employed at all times, including safety goggles. Cages were lined with non-reflective materials to eliminate risk of injury by reflection of the laser.

\subsubsection{Testing procedure}

Each cat was exposed three times on a given day to a $\mathrm{CO}_{2}$ thermal laser device for 4 consecutive days. As a control, each cat was also exposed to the visible (non-thermal) helium laser three times per day across 4 consecutive days. The helium laser was manufactured as an integrated component of the thermal laser device and used for guidance. This resulted in a total of 24 exposures for each cat, 12 to the thermal and 12 to the non-thermal laser.
After the habituation period ( $15 \mathrm{~min}$ ), three threshold tests were conducted on each cat. Testing did not commence until the cat was in the appropriate position (sternal recumbency). The laser was directed onto the exposed area of skin from a distance of $2 \mathrm{~m}$ until the cat responded either by moving away from the stimulus or exhibiting the panniculus reflex, or until the safety cut-off time was reached. Following either of these behavioural responses, the laser was turned off and the time to respond (latency) noted to the nearest $0.1 \mathrm{~s}$. For each cat the thermal laser was not re-applied until a minimum of $15 \mathrm{~min}$ had elapsed, well beyond the time required for heat decay at the site of stimulation in humans (Leandri et al., 2006). The exact time between each test varied dependent upon the activity pattern of the individual (i.e. time to sternal recumbency).

To ensure that the response observed was related to the thermal laser and not to the visible helium laser used for sighting, each cat was also exposed to the visible (non-thermal) helium laser only (i.e. the red helium laser was directed onto the exposed skin but the thermal laser was not activated) on three separate occasions randomly during each of the 4 trial days. Each helium laser test ceased when the cat responded in either of the ways identified as endpoints for thermal laser testing or when the time exceeded the safety cut-off time. Non-thermal laser tests were applied opportunistically throughout the 1-1.5 $\mathrm{h}$ thermal laser testing period and therefore did not necessarily have a 15 min interval between them.

To establish whether the device would elicit behavioural responses within an appropriate time its settings were first tested on two cats not used in the study. At $165 \mathrm{~mW}$ all responses occurred in less than $90 \mathrm{~s}$ with no evidence of reddening or skin damage. Therefore, these parameters were considered appropriate maxima for thermal laser testing of cats. For other species increased laser power has been shown to be associated with a shorter latency to respond (Herskin et al., 2009; Veissier et al., 2000). For this reason a constant low power was used to maximise the probability that any changes in latency would be identified (i.e. longer latencies would better allow variation between individuals to be identified) and to minimise the assumed negative effects of thermal stimulation at higher power settings. As skin temperature is expected to increase at a constant rate in response to $\mathrm{CO}_{2}$ laser stimulation (Veissier et al., 2000), latency to respond behaviourally to thermal stimulation was measured rather than skin temperature per se.

\subsection{Statistical analyses}

Data were analysed and transformed using the Statistical Package for the Social Sciences (SPSS) version 19.0 for Windows (IBM Inc., Chicago IL, USA). The data were not normally distributed and were therefore $\log _{10}$ transformed and re-tested and shown to be normal with homogeneity of variances. A mixed design analysis of variance (ANOVA) was used to assess whether the latency to respond varied significantly amongst tests on a given day (intra-day), amongst test days (inter-day) or between the sexes or whether there was an interaction amongst any combination of the three factors. One of the core assumptions of 
Table 1

Results of intra-class correlations for latency to respond to a thermal laser by 16 cats. Correlations reflect repeatability over three tests on any 1 day of testing (intra-day reliability) and overall repeatability for all tests on all days (across 4 consecutive days).

\begin{tabular}{|c|c|c|c|c|c|c|}
\hline \multirow[t]{2}{*}{ Day } & \multirow[t]{2}{*}{ Intra-class correlation } & \multicolumn{2}{|c|}{ 95\% confidence interval } & \multirow[t]{2}{*}{$\mathrm{DF}^{\mathrm{a}}$} & \multirow[t]{2}{*}{$F$ test value } & \multirow[t]{2}{*}{$P$ value } \\
\hline & & Lower bound & Upper bound & & & \\
\hline 1 & 0.414 & 0.105 & 0.707 & $15(30)$ & 3.118 & 0.004 \\
\hline 2 & 0.255 & -0.042 & 0.592 & $15(30)$ & 2.026 & 0.049 \\
\hline 3 & 0.334 & 0.028 & 0.652 & $15(30)$ & 2.505 & 0.016 \\
\hline 4 & 0.197 & -0.09 & 0.545 & $15(30)$ & 1.737 & 0.096 \\
\hline All days & 0.241 & 0.112 & 0.473 & 15 (165) & 4.817 & $<0.0001$ \\
\hline
\end{tabular}

a Total degrees of freedom for analyses $\left(\mathrm{DF}_{2}\right)$ shown in parentheses.

this analysis is that of sphericity. To test sphericity we used Mauchly's Test which tests for the equivalence of the hypothesised and observed variance/co-variance patterns. Data are presented in this paper as both raw mean values and transformed mean values where required and are identified appropriately.

Repeatability of the latency to respond for the cats was tested using a single measures intra-class correlation (ICC). Repeatability was assessed for the subjects on each day (intra-day repeatability) and across the 4 days using all 12 latencies (inter-day repeatability). Inter-day repeatability was also assessed using ICC for male and female cats separately to establish whether there were possible sex effects on repeatability. A Cronbach's alpha test was used to assess the reliability of the data. Differences and correlations were considered significant at $P<0.05$.

As 98\% (188/192) of the non-thermal tests exceeded the 90 s cut-off time these were not included for analysis. They were taken as indicative that latencies recorded in response to the $\mathrm{CO}_{2}$ laser were a direct result of thermal stimulation.

\section{Results}

All thermal laser exposures elicited a behavioural response within the $90 \mathrm{~s}$ allowed. Of the 192 non-thermal tests only four (2\%) resulted in a behavioural response within the $90 \mathrm{~s}$ timeframe. All four responses were associated with movement of the cat away from the light and, therefore, none were associated with the panniculus reflex. By contrast, of the 192 thermal tests 186 (97\%) were terminated as a result of the subject exhibiting the panniculus reflex.

\subsection{Latency to respond}

For all analyses, Mauchly's Test of sphericity was not significant (all $P>0.4$ ). In general, latency to respond showed substantial individual variation, with a mean response time \pm SE across the 192 thermal tests of $28.6 \pm 1.05 \mathrm{~s}$ (total range: 7.6-76.5 s). The log-transformed mean was $1.41 \pm 0.15$. Intra-day latency to respond did not significantly vary (ANOVA intra-day effect; $F_{2,28}=1.213$; $P=0.313$ ) nor was there any evidence of a change in latency over 4 consecutive days (inter-day effect; $F_{3,42}=1.918$; $P=0.141)$. Similarly there was no significant interaction between intra-day and inter-day response latencies $\left(F_{6,84}=1.298 ; P=0.287\right)$.
There was no significant effect of sex on latency to respond $\left(F_{1,14}=3.238 ; P=0.094\right)$ however there was a significant interaction between sex and inter day latency $\left(F_{3,42}=2.987 ; P=0.042\right)$. Exploration using estimated marginal means indicated that females had lower response time latencies than males on days 2 (24.6s and $31.9 \mathrm{~s}$, respectively), 3 (23.5 s and $34 \mathrm{~s}$, respectively) and 4 (21.3 s and $28.6 \mathrm{~s}$, respectively) but not on day 1 (32.1 s and $31.4 \mathrm{~s}$, respectively). Means as expressed are untransformed.

\subsection{Repeatability}

Intra-class correlations demonstrated significant intraday repeatability on the first 3 days of testing but not on the 4 th (Table 1). Similarly, inter-day repeatability was statistically significant for the 16 cats (Table 1 ). Further analysis indicated that inter-day repeatability was statistically significant for both males $\left(\right.$ ICC $=0.178 ; F_{7,77}=3.599 ; P=0.002$ ) and females $\left(\right.$ ICC $\left.=0.283 ; F_{7,77}=5.725 ; P<0.0001\right)$. With the exception of day 3, the Cronbach's alpha score exceeded 0.7 for all ICC indicating that the source data were reliable (day $3=0.6$; reliability marginal).

\section{Discussion}

This research supports the use of $\mathrm{CO}_{2}$ lasers to measure thermal nociceptive thresholds in cats. As demonstrated in other species, cats consistently exhibit a relatively simple behavioural response to thermal laser stimulation. In this regard, the panniculus reflex should be considered a useful and obvious behaviour for the testing of nociceptive thresholds in cats. The behavioural responses in this study were less marked than those reported in other species with only a minority of individuals actively withdrawing from the stimulus. Similar laser-based studies in other species have reported more active avoidance of the stimulus (e.g. kicking of the leg; Guesgen et al., 2011; Herskin et al., 2009; Veissier et al., 2000). This suggests that low power stimulation can be effective and repeatable in some species. It may also minimise the negative aspects of thermal stimulation in domestic cats.

There were no effects of test number or of test day on the latency to respond. This indicates there was no evidence of habituation or sensitisation to the stimulus, likely also related to the low power outage used. Previous studies using higher power devices have demonstrated that animals respond relatively quickly (94\% response in 
$<25$ s; Herskin et al., 2009), with a tendency towards a decreased latency in subsequent tests (Veissier et al., 2000). This study supports the notion that low power thermal stimulation results in longer latencies to respond, although higher outputs need to be explored further in domestic cats. It is unclear whether the subsequent lack of habituation resulted from a response at a lower skin temperature than required for other species (e.g. $45-55^{\circ} \mathrm{C}$ in cattle; Veissier et al., 2000) or whether it results from a more gradual increase in skin temperature which stimulates different nociceptors ( $C$ as opposed to A $\delta$ fibres) as seen in the rat (Yeomans and Proudfit, 1996). To establish this, future assessments could include thermographic images of the affected skin area. As the experimental room was not climate controlled it is possible that fluctuations in ambient temperature may also have had a small effect on rates of heating and cooling of the skin and, therefore, latency to respond.

The statistically significant repeatability demonstrated for this technique shows it to be a promising tool in assessing nociception in the cat and does not support the assertion by Veissier et al. (2000) that high power settings are absolutely required to ensure valid and reliable measures. It indicates that, although responses may be variable between individuals, the position of the individual within the cohort is predictable. In this regard single exposures (and responses) may be sufficient for any future nociceptive threshold assessments. The long latencies at lower powers may be of benefit to studies where small numbers of animals are used. For horses, it has been noted that high power thermal sources require a short cut-off time to avoid tissue damage, during which some individuals may not have responded (Love et al., 2011). This can limit the value of the data collected as slow responses are not quantified. A similar issue was noted for sheep during a laser-based trial using a high power output (Guesgen et al., 2011). In addition, where multiple factors may affect nociceptive response (e.g. age, sex or level of subcutaneous body fat), a longer latency to respond may be useful in differentiating between them.

However, low power outputs and long latencies to respond do appear to have drawbacks. A potential drawback of using a low power laser device with longer latency times is that other factors may strongly influence the response. Of particular interest is the loss of repeatability on day 4 . This test day coincided with inclement weather (a winter storm) which may explain why the cats' responses were not repeatable. A fear response to the storm may have masked the response to a less aversive event (i.e. low level thermal stimulation) for some of the cats, thus affecting repeatability on day 4. Storms and unpredictable noises have been identified as common fear inducing events for dogs (Overall et al., 2001), and cats have also been noted as having noise related fear responses (Bowen and Heath, 2005). In humans fear has been shown to induce hypoalgesia and increase the latency of a reflex withdrawal response following low intensity thermal stimulation (Rhudy et al., 2004). Similarly a conditioned fear response is known to increase latency to respond to a thermal tail flick test in rats (Seo et al., 2008). This suggests that external disturbances, particularly those which may cause stress or fear, should be controlled, wherever possible, when using a low power $\mathrm{CO}_{2}$ laser technique.

Use of this technique to establish the effectiveness of analgesia may be limited due to the wide variation in latency to respond. Current thermal techniques use the skin temperature at which a behavioural response occurs rather than the time to respond, which appears to have significantly less variation $\left(40.8 \pm 2.2^{\circ} \mathrm{C}\right.$ : Lascelles and Robertson, $2004 ; 44.4 \pm 2.5^{\circ} \mathrm{C}$ : Siao et al., 2011). Long response latencies, which may be useful for establishing variation between individuals, may result in the need to have larger sample populations for testing the effects of analgesia. Further exploration of underlying nociceptive mechanisms in cats and an investigation into the responses of individuals to low output thermal devices following surgery and administration of analgesia are required. There is also a need to explore the use of higher power laser outputs to establish if a decrease in response latency may further improve the utility of this methodology for cats.

There are numerous extraneous factors which could explain the relatively low ICC co-efficients, however these are hard to effectively explore in small cohort studies. This study showed a non-significant difference in latency to respond between males and females, but arguably suggested a trend $(P<0.1)$ that females responded more quickly than males. There was a significant interaction between sex and daily response with females responding more quickly than males on days 2, 3 and 4 but not on day 1. Therefore the influence of sex on nociceptive thresholds of cats requires further exploration. Sex has been shown to have a significant and complex interaction with age in a similar study of pain threshold in lambs (Guesgen et al., 2011). Genotype has been identified as the basis for variations in pain perception (Mogil, 1999) and phenotypic expression is also known to influence pain perception in humans (e.g. hair colour: Liem et al., 2005). Whether this effect extends to coat colour in non-human animals is currently unknown. However, we suggest that this study should be performed on a larger cohort to explore these factors further.

\section{Conclusions}

Although there are a number of potential factors that influence the response of the individual cat to thermal laser stimulation, this study demonstrated that use of a $\mathrm{CO}_{2}$ laser on a low power setting generated a repeatable response for a given individual both within and between days. However there was a significant degree of inter-individual variation and an indication that the sex of the cat may influence the response. Therefore this technique warrants further exploration using a larger cohort, specifically to address factors that may influence the response latency.

\section{Conflicts of interest}

As primary author of the manuscript: Validating the use of a carbon dioxide laser for assessing nociceptive thresholds in adult domestic cats (Felis catus). I, Mark Farnworth, declare that there are no conflicts of interest which arise as a result 
of the relationships between myself or my co-authors and our respective funding sources and industry relationships.

\section{Acknowledgement}

The authors would like to thank the staff and students at the Massey University Feline Unit for their generous provision of time and assistance.

\section{References}

Allen, C., 2004. Animal pain. Noûs 38, 617-643.

Bernstein, P., 2005. The human-cat relationship. In: Rochlitz, I. (Ed.), The Welfare of Cats. Springer, Dordrecht, pp. 47-89.

Bowen, J., Heath, S., 2005. Feline fear, anxiety and phobia problems. In: Behaviour Problems in Small Animals: Practical Advice for the Veterinary Team. Elsevier Saunders, Philadelphia, USA, pp. 163-77.

Chesterton, L.S., Barlas, P., Foster, N.E., Baxter, G.D., Wright, C.C., 2003. Gender differences in pressure pain threshold in healthy humans. Pain $101,259-266$.

Cloutier, S., Newberry, R.C., Cambridge, A.J., Tobias, K.M., 2005. Behavioural signs of postoperative pain in cats following onychectomy or tenectomy. Appl. Anim. Behav. Sci. 92, 325-335.

Dixon, M.J., Robertson, S.A., Taylor, P.M., 2002. A thermal threshold testing device for evaluation of analgesics in cats. Res. Vet. Sci. 72, 205-210.

Dixon, M.J., Taylor, P.M., Steagall, P.V.M., Brodani, J.T., Luna, S.P.L., 2007. Development of a pressure nociceptive threshold testing device for evaluation of analgesics in cats. Res. Vet. Sci. 82, 85-92.

Fillingim, R.B., Gear, R.W., 2004. Sex differences in opioid analgesia: clinical and experimental findings. Eur. J. Pain 8, 413-425.

Gagliese, L., Melzack, R., 1999. Age differences in the response to the formalin test in rats. Neurobiol. Aging 20, 699-707.

Greenspan, J.D., Craft, R.M., LeResche, L., Arendt-Nielsen, L., Berkley, K.J., Fillingim, R.B., Gold, M.S., Holdcroft, A., Lautenbacher, S., Mayer, E.A. Mogil, J.S., Murphy, A.Z., Traub, R.J., 2007. Studying sex and gender differences in pain and analgesia: a consensus report. Pain 132, S26-S45.

Grint, N.J., Murison, P.J., Coe, R.J., Waterman Pearson, A.E., 2006. Assessment of the influence of surgical technique on postoperative pain and wound tenderness in cats following ovariohysterectomy. J. Feline Med. Surg. 8, 15-21.

Guesgen, M.J., Beausoleil, N.J., Minot, E.O., Stewart, M., Jones, G., Stafford, K.J., 2011. The effects of age and sex on pain sensitivity in young lambs. Appl. Anim. Behav. Sci. 135, 51-56.

Gülsoy, M., Durak, K., Kurt, A., Karamürsel, S., Çilesiz, I., 2001. The 980nm diode laser as a new stimulant for laser evoked potentials studies. Lasers Surg. Med. 28, 244-247.

Hendricks, W.H., Wamberg, S., Tartellin, M.F., 1999. A metabolism cage for quantitative urine collection and accurate measurement of water balance in adult cats (Felis catus). J. Anim. Physiol.: A Anim. Nutr. 82, 94-105.

Herskin, M.S., Ladewig, J., Arendt-Nielsen, L., 2009. Measuring cutaneous thermal nociception in group-housed pigs using laser technique effects of laser power output. Appl. Anim. Behav. Sci. 118, 144-151.

Lascelles, B.D., Waterman, A., 1997. Analgesia in cats. In Pract. 19, 203-213.

Lascelles, B.D., Robertson, S.A., 2004. Use of thermal threshold response to evaluate the antinociceptive effects of butorphanol in cats. Am. J. Vet. Res. 65, 1085-1089.

Leandri, M., Saturno, M., Spadavecchia, L., Iannetti, G.D., Cruccu, G., Truini, A., 2006. Measurement of skin temperature after infrared laser stimulation. Neurophysiol. Clin. 36, 207-218.

Le Bars, D., Gozariu, M., Cadden, S.W., 2001. Animal models of nociception. Pharmacol. Rev. 53, 597-652.
Liem, E.B., Joiner, T.V., Tsueda, K., Sessler, D.I., 2005. Increased sensitivity to thermal pain and reduced subcutaneous lidocaine efficacy in redheads. Anesthesiology 102, 509-514.

Love, E.J., Murrell, J., Whay, H.R., 2011. Thermal and mechanical nociceptive threshold testing in horses: a review. Vet. Anaesth. Analg. 38, $3-14$.

Malmberg, A.B., Yaksh, T.L., 1992. Antinociceptive actions of spinal nonsteroidal anti-inflammatory agents on the formalin test in the rat. J. Pharmacol. Exp. Ther. 263, 136-146.

Mogil, J.S., 1999. The genetic mediation of individual differences in sensitivity to pain and its inhibition. Proc. Natl. Acad. Sci. U.S.A. 96, 7744-7751.

Overall, K.L., Dunham, A.E., Frank, D., 2001. Frequency of nonspecific clinical signs in dogs with separation anxiety, thunderstorm phobias, noise phobia, alone or in combination. J. Am. Vet. Med. Assoc. 219, 467-473.

Pinardi, G., Sierralta, F., Miranda, H.F., 2003. Atropine reverses the antinociception of nonsteroidal anti-inflammatory drugs in the tailflick test of mice. Pharmacol. Biochem. Behav. 74, 603-608.

Rhudy, J.L., Grimes, J.S., Meagher, M.W., 2004. Fear-induced hypoalgesia in humans: effects on low intensity thermal stimulation and finger temperature. J. Pain 5, 458-468.

Robertson, S.A., 2005. Managing pain in feline patients. Vet. Clin. Small Anim. 35, 129-146.

Rütgen, B.C., Stüger, H.-P., Holzmann, A., Bubna-Littitz, H., Skalicky, M., Thalhammer, J.G., 2011. Postoperative pain-associated behaviour in cats undergoing ovariohysterectomy. Vet. Med. Austria 98, 119-125.

Seo, D., Pang, M.-O., Shin, M.-S., Kim, H.-T., Choi, J.-S., 2008. Hippocampal NMDA receptors are necessary for auditory trace fear conditioning measured with conditioned hypoalgesia in rats. Behav. Brain Res. 192, 264-268.

Siao, K.T., Pypendop, B.H., Escobar, A., Stanley, S.D., Ilkiw, J.E., 2011. Effect of amatadine on oxymorphone-induced thermal antinociception in cats. J. Vet. Pharmacol. Ther. 35, 169-174.

Slingsby, L.S., Murrell, J.C., Taylor, P.M., 2010. Combination of dexmedetomidine with buprenorphine enhances the antinociceptive effect to a thermal stimulus in the cat compared with either agent alone. Vet. Anaesth. Analg. 37, 162-170.

Taylor, P.M., Robertson, S.A., Dixon, M.J., 2007. Evaluation of the use of thermal thresholds to investigate NSAID analgesia in a model of inflammatory pain in cats. J. Feline Med. Surg. 9, 313-318.

Ting, S.T.L., Earley, B., Veissier, I., Gupta, S., Crowe, M.A., 2010. Effects of burdizzo castration on $\mathrm{CO}_{2}$ laser induced thermal nociception of Holstein-Friesian calves of different ages. Appl. Anim. Behav. Sci. 126, $12-18$.

Van Soens, I., Struys, M.M., Polis, I.E., Bhatti, S.F., Van Meervenne, S.A., Martlé, V.A., Tshamala, M., Vanhaesebrouk, A.E., Van Ham, L.M., 2009. Magnetic stimulation of the radial nerve in dogs and cats with brachial plexus trauma: a report of 53 cases. Vet. J. 182, 108-113.

Veissier, I., Rushen, J., Colwell, D., de Passillé, A.M., 2000. A laser-based method for measuring thermal nociception of cattle. Appl. Anim. Behav. Sci. 66, 289-304.

Waran, N., Best, L., Williams, V., Salinsky, J., Dale, A., Clarke, N., 2007. A preliminary study of behaviour-based indicators of pain in cats. Anim. Welfare 16, 105-108.

Williams, V.M., Lascelles, B.D.X., Robson, M.C., 2005. Current attitudes to, and use of, peri-operative analgesia in dogs and cats by veterinarians in New Zealand. New Zeal. Vet. J. 53, 193-202.

Woolf, C.J., Ma, Q., 2007. Nociceptors - noxious stimulus detectors. Neuron $55,353-364$.

Yeomans, D.C., Proudfit, H.K., 1996. Nociceptive responses to high and low rates of noxious cutaneous heating are mediated by different nociceptors in the rat: electrophysiological evidence. Pain 68 , 141-150. 